SHORT COMMUNICATION

\title{
Helix Formation of Poly(phenylacetylene)s Bearing Azide Groups through Click Polymer Reaction with Optically Active Acetylenes
}

\author{
By Ken Itomi, Shinzo KobaYASHI, Kazuhide Morino, Hiroki IIDA, and Eiji YaSHIMA*
}

KEY WORDS: Click Reaction / Poly(phenylacetylene) / Induced Circular Dichroism / Helicity Induction / Helical Structure /

The $\mathrm{Cu}(\mathrm{I})$-catalyzed alkyne-azide cycloaddition, i.e. "click" reaction, has become very popular in materials and polymer science. Because of its versatility, high efficiency, and excellent functional group tolerance, ${ }^{1-4}$ a variety of functional polymers with unique architectures have been developed using the click reaction. However, the successful examples where the click reaction was employed for preparing optically active helical polymers are still scarce ${ }^{5-10}$ despite the attractive applications to chiral materials. ${ }^{11-18}$ Recently, we reported a novel approach to the synthesis of diverse optically active polymers using the click reaction. ${ }^{19}$ The click reaction was used to modify the azide pendant groups of an optically active helical poly(phenylacetylene) with various chiral acetylenes, thus producing diverse diastereomeric helical poly(phenylacetylene)s with an optical activity.

Here we report an alternative method for preparing optically active helical poly(phenylacetylene)s ${ }^{16-23}$ based on the helicity induction ${ }^{16-18,24-27}$ on optically inactive poly(phenylacetylene)s bearing azide pendant groups (poly-1 and poly-2) by the click polymer reaction using chiral acetylenes (Scheme 1). We anticipated that a preferred-handed helical structure could be induced in the optically inactive poly- $\mathbf{1}$ and poly- $\mathbf{2}$ through the covalent bonding of optically active substituents after the click polymer reaction, which could be easily detected by circular dichroism (CD) spectroscopy, and that this approach might be applicable for developing a facile system to sense the chirality of chiral acetylenes. To the best of our knowledge, this is the first example of the prevailing one-handed helix formation through the click reaction of optically inactive polymers.

\section{RESULTS AND DISCUSSION}

Optically inactive stereoregular (cis-transoidal) poly(phenylacetylene)s (poly-1 and poly-2) bearing azide groups as the pendants were prepared by the polymerization of the corresponding monomers ( $\mathbf{1}$ and 2 ) with $[\mathrm{Rh}(\mathrm{nbd}) \mathrm{Cl}]_{2}$ (nbd: norbornadiene) in chloroform in the presence of triethylamine at $30^{\circ} \mathrm{C}$ for $30 \mathrm{~min}$, giving optically inactive poly(phenylacetylene)s bearing the azide residues as the reactive pendant groups for the click reaction in 68 (poly-1) and 78\% yield (poly-2), respectively (Scheme 1). The number-average molecular weight $\left(M_{\mathrm{n}}\right)$ and its distribution $\left(M_{\mathrm{w}} / M_{\mathrm{n}}\right)$ of poly-1 and poly-2 were estimated to be $7.40 \times 10^{3}$ and 3.27 and $2.33 \times 10^{5}$ and 3.37 , respectively, as determined by sizeexclusion chromatography (SEC) using polystyrene standards in chloroform as the eluent.

The reactive azide groups of poly-1 and poly-2 were then modified with optically active acetylenes, i.e., $(R)$ - and (S)-1-phenyl-2-propyn-1-ol, by the Cu-catalyzed "click" polymer reaction to yield optically active poly-3 and poly-4, namely poly-(S)-3 and poly- $(R)-\mathbf{3}$, and poly-(S)-4 and poly- $(R)-\mathbf{4}$, respectively. The conversion of the azide groups into the triazole ones was confirmed by IR, ${ }^{1} \mathrm{H}$ NMR, and elemental analyses (see the Supporting Information). The stereoregularities of all the polymers were rich in cis-transoid judging from ${ }^{1} \mathrm{H}$ NMR spectroscopy (Figure S1). ${ }^{17,20-27}$
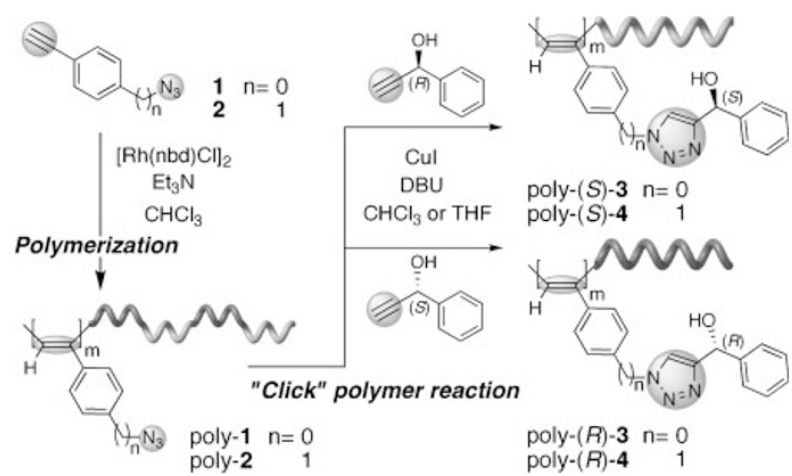

Scheme 1. Synthesis of helical poly-3 and poly-4 using click polymer reaction with optically active acetylenes. DBU: 1,8-diazabicyclo[5.4.0]-undec-7-ene.

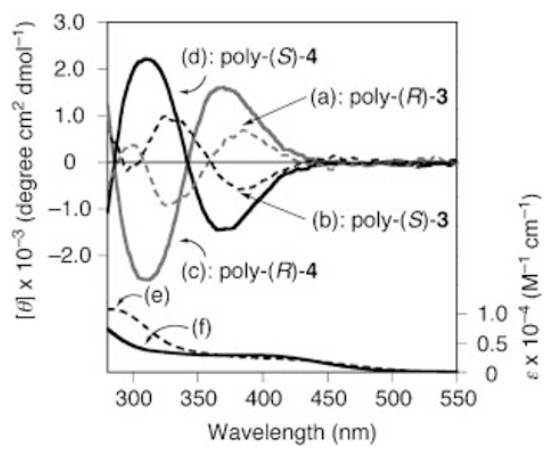

Figure 1. CD spectra of poly- $(R)-3(\mathrm{a})$, poly- $(S)-3$ (b), poly- $(R)-4$ (c), and poly-(S)-4 (d) and absorption spectra of poly-(R)-3 (e) and poly$(R)-4$ (f). The $C D$ and absorption spectra were measured in DMSO-acetic acid $(99 / 1, \mathrm{v} / \mathrm{v})$ in a $0.1-\mathrm{cm}$ quartz cell at $25^{\circ} \mathrm{C}$. The concentrations of poly-3 and poly- 4 are 0.2 and $0.5 \mathrm{mg} / \mathrm{mL}$, respectively.

Figure 1 shows the $\mathrm{CD}$ and absorption spectra of poly-3 and poly- $\mathbf{4}$ in dimethyl sulfoxide (DMSO) containing a small amount of acetic acid, which was used due to the solubility problem of these polymers in DMSO. Poly-3 and poly-4 showed a difference in their CD and absorption spectral patterns because of the methylene linker of poly- 4 that likely reduced the $\pi$-conjugated length of the polymer. Poly- $(S)-\mathbf{3}$ and poly- $(R)-\mathbf{3}$ exhibited the split-type induced CDs (ICDs) in the conjugated polymer backbone regions that are mirror image from each other. Poly- $(S)-\mathbf{4}$ and poly- $(R)-\mathbf{4}$ also showed mirror imaged ICDs. Poly-1 and poly-2 are totally optically inactive, but are dynamically racemic helical polymers composed of

Department of Molecular Design and Engineering, Graduate School of Engineering, Nagoya University, Chikusa-ku, Nagoya 464-8603, Japan *To whom correspondence should be addressed (Tel: +81-52-789-4495, Fax: +81-52-789-3185, E-mail: yashima@apchem.nagoya-u.ac.jp). 

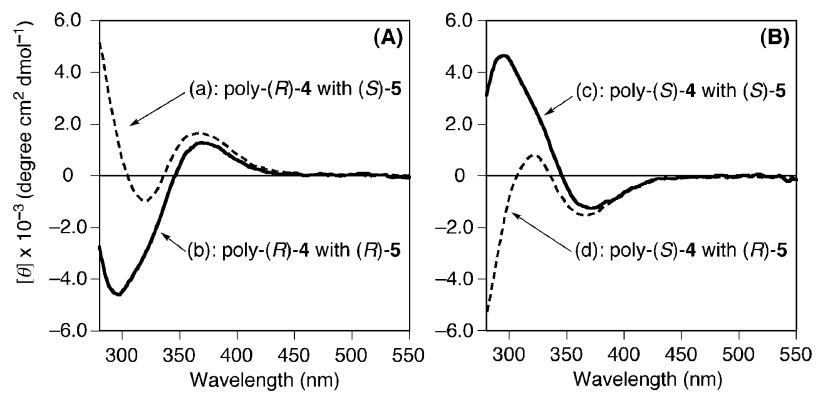

Figure 2. CD spectra of poly-(R)-4 with (A) (S)- (a) and (R)-5 (b) and poly$(S)-4$ with (B) $(S)$ - (c) and $(R)-5$ (d) (50 equiv) in DMSO in a $0.1-\mathrm{cm}$ quartz cell at $25^{\circ} \mathrm{C}$. Polymer concentration is $0.5 \mathrm{mg} / \mathrm{mL}$.

interconvertible right and left-handed helical conformations separated by the rarely occurring helical reversals. ${ }^{12,16-18}$ Therefore, the "click" modification of the azide pendant groups of the polymers with the optically active acetylenes biased the main chain to form a preferred-handed helical conformation, resulting in a characteristic ICD depending on the stereochemistry of the chiral acetylenes. These characteristic ICDs indicate that poly-1 and poly-2 can be used as a novel chirality sensor for chiral acetylenes through the click polymer reaction.

We next preliminarily investigated the diastereomeric complexation of the optically active poly- $\mathbf{4}$ with chiral acids through interactions with its pendant alcohol and triazole units. We found that the polymer interacted with $(R)$ - and $(S)$-mandelic acid $(\mathbf{5})$ and the diastereomeric complexation resulted in obvious changes in its ICD as previously reported for poly(phenylacetylene) bearing optically active norephedrine residues in the presence of $5^{28,29}$ Figure 2 shows the CD spectra of poly-4 in the presence of $(R)$ - and $(S)-5$ (50 equiv) in DMSO. Poly-4 responded to the chirality of the acid $\mathbf{5}$ and the diastereomeric complexes showed different ICD patterns from those of the original polymers. The ICD changes were observed in the presence of a small amount of $\mathbf{5}$ ( 0.25 equiv) (Figure S2). Poly-3 also responded to the chirality of $\mathbf{5}$ showing the changes in its $\mathrm{CD}$ spectral pattern due to the diastereomeric complexation (Figure S3).

In conclusion, we have developed a facile method to prepare optically active helical poly(phenylacetylene)s via the click polymer reaction of optically inactive azide-bound poly(phenylacetylene)s with chiral acetylenes. The resulting poly(phenylacetylene)s formed a preferred-handed helical conformation induced by the covalently bonded chiral triazole units and exhibited ICDs whose Cotton effect signs can be used to sense the chirality of the chiral acetylenes. We expect that this strategy developed in this study will be applicable for developing more effective chiralityresponsive polyacetylenes by introducing the reactive azide as well as acetylene units as the pendant groups for further modification by the click polymer reaction with optically active functional acetylenes and azide derivatives, respectively, which will further provide novel chiral materials for enantioselective adsorbents and catalysts.

Acknowledgment. This work was supported in part by the Global COE Program "Elucidation and Design of Materials and Molecular Functions" from the Ministry of Education, Culture, Sports, Science and Technology and Grant-in-Aid for Scientific Research from the Japan Society for the Promotion of Science (JSPS) and the Asahi Glass Foundation (E.Y.).
Electronic Supporting Information Available: Experimental section and supplementary data. Figures S1-S5. These materials are available via. the Internet at http://www.spsj.or.jp/c5/pj/pj.htm.

Received: September 11, 2008

Accepted: October 17, 2008

Published: December 5, 2008

\section{REFERENCES}

1. J. E. Moses and A. D. Moorhouse, Chem. Soc. Rev., 1249 (2007)

2. H. Nandivada, X. Jiang, and J. Lahann, Adv. Mater., 19, 2197 (2007).

3. D. Fournier, R. Hoogenboom, and U. S. Schubert, Chem. Soc. Rev., 1369 (2007).

4. J.-F. Lutz, Angew. Chem., Int. Ed., 46, 1018 (2007).

5. M. Kümin, L.-S. Sonntag, and H. Wennemers, J. Am. Chem. Soc. 129, 466 (2007).

6. M. Ikeda, T. Hasegawa, M. Numata, K. Sugikawa, K. Sakurai, M. Fujiki, and S. Shinkai, J. Am. Chem. Soc., 129, 3979 (2007).

7. E. Schwartz, H. J. Kitto, R. d. Gelder, R. J. M. Nolte, A. E. Rowan, and J. J. L. M. Cornelissen, J. Mater. Chem., 17, 1876 (2007).

8. R. M. Meudtner, M. Ostermeier, R. Goddard, C. Limberg, and S. Hecht, Chem. Eur. J., 13, 9834 (2007).

9. R. M. Meudtner and S. Hecht, Macromol. Rapid Commun., 29, 347 (2008).

10. R. M. Meudtner and S. Hecht, Angew. Chem., Int. Ed., 47, 4926 (2008).

11. Y. Okamoto and E. Yashima, Angew. Chem., Int. Ed., 37, 1020 (1998).

12. M. M. Green, K.-S. Cheon, S.-Y. Yang, J.-W. Park, S. Swansburg, and W. Liu, Acc. Chem. Res., 34, 672 (2001).

13. T. Nakano and Y. Okamoto, Chem. Rev., 101, 4013 (2001).

14. J. J. L. M. Cornelissen, A. E. Rowan, R. J. M. Nolte, and N. A. J. M. Sommerdijk, Chem. Rev., 101, 4039 (2001).

15. M. Fujiki, J. R. Koe, K. Terao, T. Sato, A. Teramoto, and J. Watanabe, Polym. J., 35, 297 (2003).

16. K. Maeda and E. Yashima, Top. Curr. Chem., 265, 47 (2006).

17. E. Yashima and K. Maeda, Macromolecules, 41, 3 (2008).

18. E. Yashima, K. Maeda, and Y. Furusho, Acc. Chem. Res., 41, 1166 (2008).

19. S. Kobayashi, K. Itomi, K. Morino, H. Iida, and E. Yashima, Chem. Commun., 3019 (2008).

20. R. Nomura, H. Nakako, and T. Masuda, J. Mol. Catal. A: Chem., 190, 197 (2002).

21. J. W. Y. Lam and B. Z. Tang, Acc. Chem. Res., 38, 745 (2005).

22. T. Aoki and T. Kaneko, Polym. J., 37, 717 (2005).

23. J. G. Rudick and V. Percec, New J. Chem., 31, 1083 (2007).

24. E. Yashima, T. Matsushima, and Y. Okamoto, J. Am. Chem. Soc., 117, 11596 (1995)

25. E. Yashima, H. Goto, and Y. Okamoto, Polym. J., 30, 69 (1998).

26. K. Morino, K. Maeda, Y. Okamoto, E. Yashima, and T. Sato, Chem. Eur. J., 8, 5112 (2002).

27. K. Maeda, K. Morino, Y. Okamoto, T. Sato, and E. Yashima, J. Am Chem. Soc., 126, 4329 (2004).

28. E. Yashima, Y. Maeda, and Y. Okamoto, J. Am. Chem. Soc., 120, 8895 (1998).

29. E. Yashima, Y. Maeda, and Y. Okamoto, Polym. J., 31, 1033 (1999). 